\title{
FERRAMENTA DIGITAL PARA O ENSINO E O PLANEJAMENTO DE UMA COLEÇÃO DE MODA ${ }^{1}$
}

\author{
DIGITAL TOOL FOR TEACHING AND THE \\ PLANNING OF A FASHION COLLECTION
}

\section{Gabriel Rodrigues Felipetto ${ }^{2}$, Rubiana de Quadros Sandri ${ }^{3}$, Ricardo Frohlich da Silva Taís Steffenello Ghislenii e Elsbeth Léia Spode Becker ${ }^{6}$}

\section{RESUMO}

No atual cenário de mudanças e a prática docente tem grande potencial para renovar a educação e proporcionar novas ferramentas e metodologias de ensino. O objetivo principal neste projeto foi criar uma ferramenta digital de ensino aplicada nos cursos de Moda para a criação de uma Coleção de Moda. A metodologia foi embasada na pesquisa qualitativa para compor o planejamento das etapas imprescindíveis para o desenvolvimento de uma ferramenta útil para o ensino e o planejamento de uma Coleção de Moda. A criação da ferramenta foi com a utilização do motor gráfico Unity com programação em linguagem C\# no Microsoft Visual Studio. Na modelagem foi utilizado o software 3ds Max 9. A criação do cenário se baseou na Teoria das Cinco Peles ou a Teoria de Hundertwasser (1964). O resultado consistiu na composição de uma ferramenta destinada ao ensino de Moda, para a criação de uma Coleção de Moda. A ferramenta recria o espaço físico, com ambientes e utensílios, necessário para integrar um ateliê de Moda ou parte de uma indústria.

Palavras-chave: Jogos Digitais; Design de Moda; Ensino.

\section{ABSTRACT}

In the current scenario of changes, the teaching practice has great potential to renew education and provide new teaching tools and methodologies. The main objective of this project was to create a digital teaching tool applied to fashion courses to create a fashion collection. The methodology was based on qualitative research to compose the planning of the essential steps for the development of a useful tool for teaching and planning a Fashion Collection. The tool was created using the Unity graphics engine with $C$ \# programming in Microsoft Visual Studio. The 3ds Max 9 software was used in the modeling. The creation of the scenario was based on the Theory of the Five Skins or the Theory of Hundertwasser (1964). The result was the composition of a tool designed to teach fashion, to create a fashion collection. The tool recreates the physical space, with environments and utensils, necessary to integrate a fashion studio or part of an industry.

Keywords: Digital Games; Fashion design; Teaching.

\footnotetext{
${ }^{1}$ Trabalho de Iniciação Científica. Bolsa de Iniciação Científica Edital 13/2019 PROBIC/FAPERGS. Projeto: TECNOLOGIA APLICADA À MODA: NOVAS ESTRATÉGIAS DE ENSINO NOS CURSOS DE MODA

${ }^{2}$ Acadêmico do Curso de Jogos Digitais - Universidade Franciscana - UFN. E-mail: gfelipetto@gmail.com

${ }^{3}$ Professora do Curso de Design de Moda - Universidade Franciscana - UFN. E-mail: ruby_moda@yahoo.com.br

${ }^{4}$ Professor do Curso de Jogos Digitais - Universidade Franciscana - UFN. E-mail: ricardo.frohlich@ufn.edu.br

${ }^{5}$ Professora do Curso de Publicidade e Propaganda - Universidade Franciscana - UFN. E-mail: taisghisleni@yahoo.com.br

${ }^{6}$ Professora do Mestrado em Ensino de Humanidades e Linguagens - Universidade Franciscana - UFN. E-mail: elsbeth.go@ gmail.com
} 


\section{INTRODUÇÃO}

A tecnologia acompanha a Moda! Basta observar as tendências para as próximas estações, para perceber que suas novidades estão próximas ao que antes estava restrito aos filmes de ficção científica. A área da Moda utiliza as tecnologias, principalmente as digitais, tanto nas pesquisas conceituais e experimentais como no desenvolvimento de elementos, exemplo disso são os tecidos inteligentes e os wearable computers (ou wearcomps) da Moda. Ou seja, os "aparatos tecnológicos que congregam desde elementos computadorizados inseridos nas tramas dos tecidos até objetos de comunicação acoplados ao corpo por meio por meio das roupas” (AVELAR, 2011, p. 149). As tecnologias tornam-se protagonistas neste novo cenário.

As novidades surgem a cada instante e incluem desde tecidos com proteção solar, tecidos que ampliam o desempenho de atletas, termorreguladores, termo cromáticos, que medem os batimentos cardíacos, roupas que interagem com o usuário e a utilização de robô com inteligência artificial como modelo, como é o caso da empresa CuteCircuit ${ }^{7}$ que criou o protótipo da camiseta Hung Shirt que interage com o usuário, a sensação e a intensidade do abraço chegarão à distância, bastando apenas receber a ligação (OLIVEIRA, 2014, p. 113).

E, outro aspecto que começa a ser evidenciado é a ênfase para a Moda sustentável, que exige um consumo e uma produção consciente. Pode-se assim, afirmar que o futuro da moda será a tecnologia e a sustentabilidade. A inovação e a tecnologia são elementos imprescindíveis para que a indústria da moda consiga, em um futuro próximo, criar processos mais sustentáveis. Como afirma o designer visionário de Moda Hussein Chalayan em entrevista à Agência Aldeia" , "apenas a tecnologia nos permite criar novas combinações, estabelecer novos relacionamentos e novas interações".

De acordo com Avelar (2011) as novas tecnologias serão fundamentais para falar da Moda como o principal elemento do "novo". E, esse "novo" atua nas dimensões da cadeia produtiva e também, nas mudanças de paradigmas captados pela criação, como a sensação.

A Revolução Digital e a Inteligência Artificial trouxeram transformações para a humanidade. Castells (1999, p. 403) reforça que existe hoje uma estrita ligação entre espaço e tempo, dada pela sociedade em rede. A globalização e as tecnologias da informação são responsáveis por isso, na medida em que permeiam a vida cotidiana de todas as partes que compõem o sistema global. Cabe salientar que a relação entre esse impacto e o ensino aprendizagem de Design de Moda é um dos caminhos para compreender como acompanhar tal avanço.

A moda, desde o seu surgimento até os dias de hoje tem o princípio da velocidade, da novidade, do efêmero e também o de tornar supérfluos seus produtos rapidamente. A tecnologia também tem o mesmo princípio e precisam aliar-se para dar conta dos desafios do setor que, além de manter

\footnotetext{
${ }^{7}$ Site da empresa onde pode ser vista esta camiseta e outros protótipos tecnológicos: http://www.cutecircuit.com/

${ }^{8}$ A Aldeia é uma agência com vasta expertise na indústria da moda e lifestyle: http://aldeia.biz/
} 
inovação, também precisam formar profissionais e se relacionar com o consumidor. Pois é evidente a percepção de quanto mudou a forma como projetamos, consumimos e nos envolvemos com a moda.

Assim como a sociedade, a moda está em constante evolução, o ensino de moda também precisa acompanhar este desenvolvimento e se adequar à nova realidade. Conforme Guerreiro (2015) o conhecimento se recicla e aparecem novas possibilidades que nunca antes haviam sido imaginadas. $\mathrm{O}$ autor afirma que a inovação é, hoje em dia, um valor agregado, seguro e confiável para o crescimento profissional, e esse se dá pela capacidade de adaptação dos designers às diferentes circunstâncias.

A partir das considerações acima, percebe-se a necessidade da revisão permanente e atualizada das mudanças sociais, das novas metodologias, técnicas e ferramentas que surgem para lidar com as manifestações transitórias referentes à moda (ORTUÑO apud SANCHES 2017, p. 11).

Diante deste cenário, ou seja, a partir da percepção de que a tecnologia influencia a moda, cabe projetar a criação de uma ferramenta digital de ensino aplicada nos cursos de Moda para a criação de uma Coleção de Moda.

\section{REVISÃO DE LITERATURA}

\section{CRIAÇÃO DE FERRAMENTAS DIGITAIS PARA O ENSINO}

Ferramentas digitais são tecnologias computacionais e entendidas como tudo aquilo que é utilizado para que haja comunicação entre o homem e o computador como tablets, smartphones e outros diversos aparelhos tecnológicos (GROSSI et al., 2018). As tecnologias computacionais oportunizam interatividade, produção de conhecimento coletivo e observância de tempos e espaços de aprendizagem diferenciados, características que são fundamentais para a efetividade do processo educativo, caso sejam subsidiadas por abordagens pedagógicas. A utilização de ferramentas digitais surgiu como uma alternativa capaz de trazer um ganho significativo de qualidade ao processo ensino-aprendizagem, que oferecem a oportunidade de ampliar o potencial do uso de imagens, animações e interatividade, além de resgatar o aspecto lúdico e prazeroso da aprendizagem.

As ferramentas digitais podem viabilizar no ciclo de aprendizado as vivências da ação, reflexão, teorização e planejamento (ou prática) daquilo que se quer ensinar e aprender. E, consequentemente, a ferramenta bem estruturada e corretamente aplicada proporciona resultados muito ricos, em termos de assimilação ou reformulação de conceitos (GROSSI et al., 2018).

Assim, no campo educacional, com mais intensidade nas últimas três décadas, vem sendo inserido o uso de tecnologia para melhorar o processo ensino aprendizagem. Vídeos, jogos, retroprojetores, microcomputadores, filmadoras, câmeras e impressoras foram os primeiros. E, mais intensamente, na segunda década do século XXI, tem-se uma variedade ainda maior de aparelhos, periféricos, aplicativos, softwares, sites que quando bem utilizados, com proposta e planejamento 
bem direcionados, completam o fazer pedagógico. Tem-se acesso a uma variedade de Smartphones, tablets, notebooks, mesa digital, lousa digital, caneta digital, aplicativos, softwares, makerspaces, portais, sites e plataformas (GROSSI et al., 2018).

Neste contexto, os jogos ganham espaço como ferramenta digital de ensino, amplamente utilizada em escolas e cursos de graduação. O computador e a internet ampliam a representação da realidade, abrindo possibilidades para um novo enfoque educacional baseado em jogos, permitindo a exploração de diversos recursos multimídia. Os jogos como ferramenta digital de ensino é uma categoria que transcende o entretenimento e ganha a denominação "jogo sério", uma tradução literal do inglês "serious game". Segundo Machado et al. (2010), apesar de não haver uma definição precisa do termo serious games, essa classe de jogos visa, principalmente, simular situações práticas do dia a dia, com o objetivo de proporcionar o treinamento de profissionais, a tomada de decisão em situações críticas, a conscientização de crianças, jovens e adultos, e a educação em temas específicos.

Ademais, tais jogos conhecidos como serious games, utilizam a conhecida estratégia da indústria de jogos para tornar essas simulações mais atraentes, ao mesmo tempo em que oferecem atividades que favorecem a construção de conceitos e a estimulação de funções psicomotoras. Deste modo, o termo serious games passou a ser utilizado para identificar os jogos com um propósito específico, ou seja, jogos que extrapolam a ideia de entretenimento e oferecem outros tipos de experiências, como aquelas voltadas ao aprendizado e ao treinamento (MACHADO et al., 2010).

Botelho (2014) destaca que ferramentas digitais como os jogos, por exemplo, podem ser usadas de diferentes formas, para treinamento de habilidades operacionais, conscientização e reforço motivacional, desenvolvimento de insight e percepção, treinamento em comunicação e cooperação, integração e aplicação prática de conceitos aprendidos e até mesmo a avaliação de aprendizagem.

Para Silveira; Barone (2018), as ferramentas podem ser empregados em uma variedade de propósitos dentro do contexto de aprendizado. Um dos usos básicos e muito importantes é a possibilidade de construir-se a autoconfiança, sendo que, até mesmo o mais simplório das ferramentas pode ser empregada para proporcionar informações factuais e praticar habilidades, conferindo destreza e competência. Os jogos educativos podem despertar no aluno: motivação, estímulo, curiosidade, interesse em aprender e, dessa forma, o aluno constrói seu conhecimento de maneira lúdica e prazerosa.

Portanto, a utilização de ferramentas digitais, como os jogos, modificam a dinâmica do ensino, as estratégias e o comportamento de alunos e professores. A possibilidade de simulação que os jogos de computador e internet oferecem, acentuam três características básicas dos jogos em geral: a fantasia, a curiosidade, e o desafio. Com a possibilidade de imersão que o computador oferece, o aluno entra no jogo, assume um papel realizando uma vivência, onde ele é levado a se envolver com a fantasia, na medida em que existe uma analogia, uma metáfora com a realidade (VILA; SANTANDER, 2013). 
"É uma forma de aprender fazendo, no qual o participante pode assumir um papel ativo, por meio do exercício virtual de funções e papéis, num contexto de atividades em grupo, desenvolvendo diversas competências de forma integrada e simultânea" (VILA; SANTANDER, 2013, p. 15).

Apesar de haver grande diversidade de jogos indicados como ferramentas de ensino, é importante observar, também, que além dos conteúdos específicos, há o desenvolvimento de posturas bastante valorizados atualmente, como análise de estratégias, empreendedorismo e inovação.

\section{ITINERÁRIO PARA PLANEJAMENTO E CRIAÇÃO DE COLEÇÃO DE MODA}

A criação de uma Coleção de Moda perpassa um cenário complexo e, nesse sentido, a natureza transversal e dinâmica do design pode facilitar a decodificação da realidade, auxiliando nas diretrizes que guiem o planejamento do projeto.

Projetar significa antever o futuro, planejar algo que ainda não se conhece. No decorrer da execução do projeto, as decisões se conectam umas às outras, inserindo novas informações e se modificando até verificar sua viabilidade, processo que acontece de forma cíclica e interativa.

No contexto da indústria, o planejamento e desenvolvimento de produtos de vestuário de Moda se desdobram de maneira complexa e acelerada e autores como Montemezzo (2003), Jones (2005), Barcaro (2008), Sorger e Udale (2009), Renfrew e Renfew (2010) e Treptow (2013) são unânimes ao destacarem o planejamento como etapa imprescindível para dar conta do cenário acelerado.

Montemezzo(2003) destaca o planejamento em cinco etapas. A preparação é a primeira, na qual é realizada a coleta de dados de comportamento, definido o problema, feita a pesquisa de tendências, materiais e tecnologia, além da definição do conceito gerador, ou seja, da linguagem visual. A etapa seguinte é a geração, fase em que são realizados os esboços, os estudos de modelos e as configurações. Em seguida, vem a avaliação de acordo com as especificações do projeto. A etapa posterior é a concretização, o desenvolvimento tridimensional para experimentação, custo e correção adequações. A última é a etapa da documentação para a produção, a realização da ficha técnica definitiva e confecção da peça piloto.

Jones (2005) apresenta três grandes etapas: o briefing, em que se apresentam as metas e os objetivos, em seguida a fase da inspiração, a fase da apresentação e, por fim, a avaliação.

Barcaro(2008) define como etapa inicial o portfólio das coleções, na qual são realizadas análises de marcas, investimentos e tendências. Na etapa seguinte, sistematização das coleções, considera importante a escolha do número de modelos para o mostruário, definição dos tecidos e cores, além do cronograma operacional. Segue, então, o desenvolvimento da coleção, iniciam-se os esboços e desenhos, a escolha de acessórios e a criação das peças piloto. Nesse momento é realizada a revisão das peças, distribuição e mostra da coleção. A finalização do projeto prevê a campanha, a produção e a compra e, por fim, a entrega da coleção. 
Sorger e Udale (2009) iniciam a partir da pesquisa, sendo elas a de tendências e a de mercado. Posteriormente, inicia-se a geração de alternativas, por meio dos esboços, depois a modelagem e a pilotagem. Por fim, a confecção e a finalização da coleção.

Renfrew e Renfrew (2010) escrevem que uma coleção de moda exige muita pesquisa, investigação e planejamento. Inicia-se o processo pelo briefing, em seguida vem a modelagem, o protótipo. Destacam os processos comerciais que envolvem uma coleção de moda.

Treptow (2013) descreve as quatro etapas detalhadamente. Inicia o projeto com a etapa do planejamento, que confere a reunião de planejamento, o cronograma, o parâmetro e a dimensão da coleção. Também faz parte da etapa do planejamento, o briefing e a pesquisa de tendências. A segunda etapa é a do design, a qual é composta por inspiração, seleção de cores, tecidos, aviamentos. Além disso, a autora introduz nessa etapa os elementos e princípios do design, os elementos de estilo, que auxiliam na criação dos esboços, dos desenhos de moda, desenho técnico. A terceira etapa é a do desenvolvimento, referente à modelagem, a confecção do protótipo, aprovação, graduação, encaixe, a realização da ficha técnica, além da formação de preço, a confecção do mostruário e a produção. Na quarta e última etapa, Treptow (2013) dá ênfase para a promoção e comercialização e são considerados o lançamento, a divulgação, a comercialização, as entregas e a reunião de feedback.

Apesar de haver metodologias projetuais para o desenvolvimento de coleções de moda, nota-se que, muitas vezes, no processo de planejamento de um projeto, as etapas acontecem em ordem inversa, e há casos em que se opta por eliminar etapas que são determinantes para se obter êxito na coleção. Afinal, são etapas intermediárias para a aplicação de diversos saberes que dão consistência ao projeto. Por consequência, é relevante a busca por metodologias, ferramentas que possam auxiliar projetos na área de moda, para acompanhar suas manifestações cíclicas.

\section{METODOLOGIA}

A metodologia foi embasada na pesquisa qualitativa para compor o planejamento das etapas imprescindíveis para a criação e o desenvolvimento da ferramenta para o ensino de Moda.

Para desenvolver este projeto foi realizada uma pesquisa bibliográfica sobre o ensino de Moda e, especialmente, o itinerário para a criação de uma Coleção de Moda, a partir dos Montemezzo (2003), Jones (2005), Barcaro (2008), Sorger e Udale (2009), Renfrew (2010) e Treptow (2013) entre outros.

$\mathrm{Na}$ sequência foi organizada a proposta para a criação de um cenário virtual para compor a ferramenta de ensino para a criação de uma Coleção de Moda, baseada em Chandler (2012), que é dividida em quatro etapas gerais.

A primeira etapa - pré-produção -, em que são definidos o conceito da ferramenta, incluindo sua plataforma, gênero, elementos básicos de jogabilidade e protótipo, os requisitos de funcionamento, 
incluindo a definição dos recursos desejáveis na ferramenta e sua hierarquização de necessidades para as etapas da criação de uma Coleção de Moda

A segunda etapa - produção -, em que são desenvolvidos os elementos propostos na fase anterior.

A terceira etapa - testes, em que ocorre a verificação do funcionamento correto do material desenvolvido na etapa anterior e sua correção.

A quarta etapa - pós-produção -, em que é preparado um kit de fechamento do projeto, contendo todos os conteúdos necessários para a efetivação de uma ferramenta de ensino.

$\mathrm{Na}$ criação da ferramenta foi utilizado o motor gráfico Unity, 3ds Max (SILVA; AGUIAR, 2010). Para a criação dos ambientes da ferramenta, foram desenvolvidos vários cenários inspirados nas fábricas, ateliês, passarelas e salões da Moda. A criação do cenário se baseou na Teoria das Cinco Peles ou a Teoria de Hundertwasser (1964), revelada na arquitetura e na filosofia da interação entre homem e natureza e nas questões ambientais. A essência da Teoria de Hundertwasser reside na motivação da transformação do seu habitat, reivindicando o direito do homem a exercer sua criatividade habitual e contrapondo o reflexo apelativo do consumidor cego de produtos industriais em massa.

\section{DESENVOLVIMENTO DAS ETAPAS NA CRIAÇÃO DA FERRAMENTA}

A partir da pesquisa bibliográfica sobre o ensino de Moda e, especialmente, o itinerário para a criação de uma Coleção de Moda, baseada em Montemezzo (2003), Jones (2005), Barcaro (2008), Sorger e Udale (2009), Renfrew (2010) e Treptow (2013) entre outros, a ferramenta foi planejada para motivar a participação do discente em todas as etapas a partir de cinco princípios: compreender o real motivo de aprender o método aplicado à criação de uma Coleção de Moda; motivar para a identificação todos os elementos que podem melhorar a Coleção; valorizar os conhecimentos de outras disciplinas no contexto da criação; possibilitar a diversidade na criação; envolver ativamente em todo o processo da criação, desde a pesquisa até a Coleção de Moda pronta.

Na sequência, baseada em Chandler (2012), na primeira etapa, pré-produção, do ciclo de desenvolvimento da ferramenta de ensino foram definidas três fases: conceitos, requisitos e planejamento. $\mathrm{Na}$ fase do conceito foi definido o gênero da ferramenta e sua plataforma de hardware. Na criação da ferramenta foi utilizado o motor gráfico Unity, 3ds Max (SILVA; AGUIAR, 2010) e estabelecidos alguns elementos básicos de sua jogabilidade. Esses elementos se constituíram no esquema de controle, cenários, mecânica de jogo da ferramenta e possíveis atrativos para atrair a atenção e motivar a criatividade do discente. Depois de estabelecidos esses conceitos, foram desenvolvidos protótipos digitais, para averiguação dos elementos propostos e ajustes necessários para equacionar possíveis problemas. Nessa fase dos requisitos da ferramenta, foram determinados os recursos básicos de arte, design e engenharia necessários para a produção da ferramenta, especialmente, a composição dos cenários 
inspirados na Teoria de Hundertwasser (1964) revelada na interação entre homem e natureza. Na fase do planejamento foi desenvolvido um cronograma de execução de oito meses.

$\mathrm{Na}$ segunda etapa, produção, foram desenvolvidos os elementos propostos na fase anterior relacionados as fases da criação da Coleção de Moda, figurinos, estética, cenários e especificações de desenvolvimento (CHANDLER, 2012).

A terceira etapa, testes, foi realizada a verificação do funcionamento correto do material desenvolvido na etapa anterior e sua correção. Foram simuladas todas as etapas previstas na ferramenta para possibilitar a criação de uma Coleção de Moda e testados os diferentes elementos que a ferramenta deve permitir a inclusão, como códigos de computador, modelos tridimensionais, sons e vídeos, e sua integração (CHANDLER, 2012).

$\mathrm{Na}$ quarta etapa, pós-produção, foi preparado um kit de fechamento do projeto, contendo todos os conteúdos necessários para a efetivação de uma ferramenta de ensino (CHANDLER, 2012). Portanto, o kit do projeto apresenta cenários da ferramenta e investe em ambientes que coadunam aspectos do imaginário industrial e ambiental e, desta forma, foi possível idealizar uma fábrica têxtil sustentável e futurista.

\section{RESULTADOS E DISCUSSÃO}

Os resultados apresentados referem-se à ferramenta de ensino e, especialmente, aos cenários e a estética, com o intuito de mostrar a ferramenta e seu funcionamento e inserção no ensino para a criação de uma Coleção de Moda. Portanto, as etapas mencionadas nesta seção referem-se àquelas que pretende-se que os discentes alcancem no desenvolvimento da prática de criação para a Moda.

O primeiro ambiente é o saguão principal, onde está o maquinário da indústria têxtil junto a árvores para indicar a ideia de natureza e a necessidade da preservação ambiental. No segundo ambiente encontra-se uma série de manequins e uma mesa no centro, indicando a sala de planejamento e criação de moda. No último ambiente está a sala de pesquisas, representando uma sala de reuniões, com "puffs", manequins e um quadro. A partir da criação da ferramenta é possível inferir que os recursos digitais trazem uma maneira mais dinâmica e lúdica para a aprendizagem do aluno em sala de aula. Neste sentido, a ferramenta proporciona a integração das tecnologias ao processo de ensino e torna mais fácil realizar atividades de pesquisa, de produção e de troca de conteúdo, ampliando as possibilidades já existentes para criar a coleção de moda.

A tela inicial apresenta o ícone "Iniciar" e o aluno poderá abrir a ferramenta e iniciar as atividades de todas as etapas que compõem o planejamento de uma Coleção de Moda (Figura 1). 
Figura 1 - Tela inicial da ferramenta de ensino "Coleção de Moda".

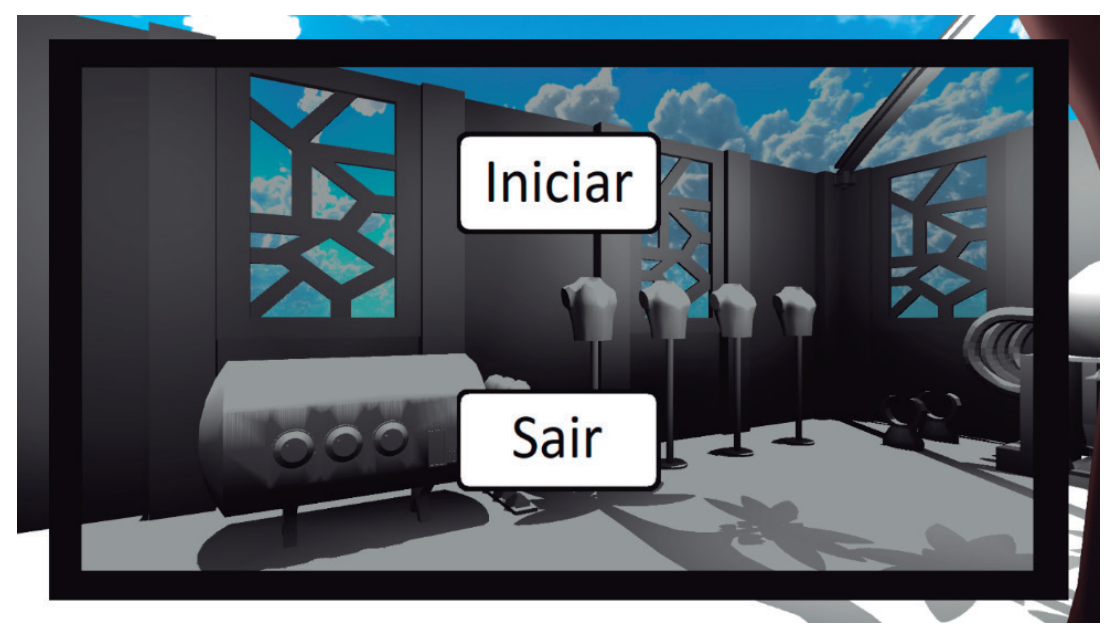

A partir da tela inicial, tem-se acesso a todas as etapas da ferramenta, conforme descritas e ilustradas na sequência. De início, no saguão principal (Figura 2), encontram-se máquinas movidas a energia sustentável e, no centro, árvores que sobressaem o teto da fábrica e remetendo a ideia de amplidão, de luz natural e sensação de liberdade, para criar em meio à um ambiente sustentável e em harmonia com a natureza e, desta forma, projetar coleções que sejam alinhadas com a ideia e a cultura da preservação dos recursos naturais. Na sequência, há ambientes em outras duas salas, sendo uma destinada à reuniões e a outra com manequins para testagens e planejamento.

Figura 2 - Saguão principal que remete à ideia de sustentabilidade

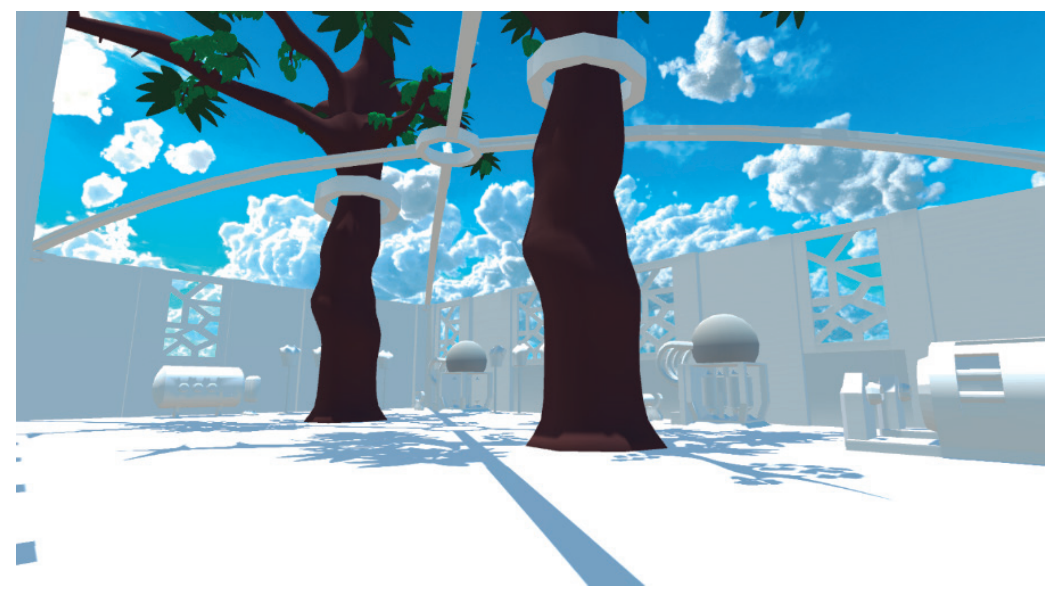

\section{Etapa 1 - Planejamento}

Game Design: Esta etapa consiste no planejamento da Coleção de Moda e foram projetadas input fields para que o aluno possa preencher com as informações e as descrições que pretende dar à sua coleção, tais como, cronograma, segmentação, parâmetro e dimensão (Figura 3).

Programação: Para programar esta etapa foi utilizado um canvas único para a mesma, ensedas as imagens, input fields e os botões, onde o aluno pode acessá-lo se aproximando da planilha e pressionando a tecla "E" do teclado. 
Arte: Sendo esta a etapa do planejamento, pensamos em usar uma planilha como representação da HUD(ou heads-up display, é o termo dado para a representação dos objetos no jogo)

Figura 3 - a) Sala dos manequins e de planejamento inicial da Coleção de Moda;

b) HUD que aparecerá ao aluno quando interagir com a planilha na sala de manequins.

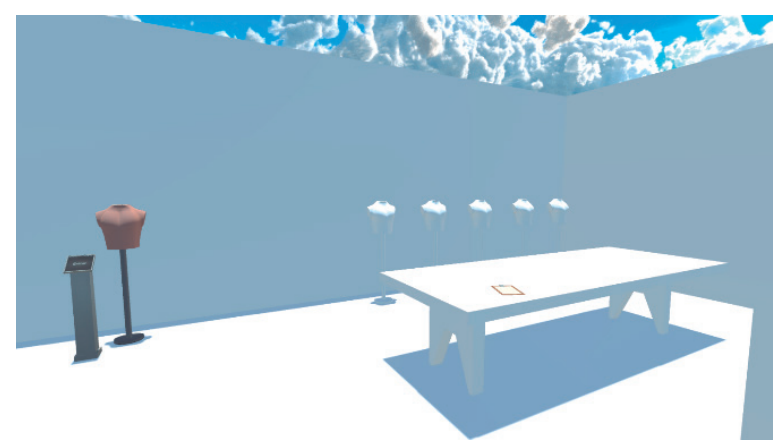

(a)

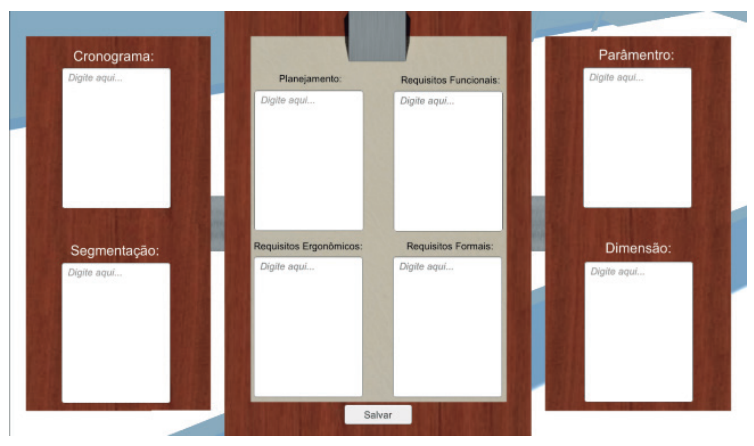

(b)

\section{Etapa 2 - Pesquisas}

Game Design: Esta etapa apoia-se em pesquisas externas para a coleção, tais como, comportamento, mercado, tendências e sustentabilidade. Assim, foi criado um quadro de anotações no qual o aluno poderá interagir (Figura 4). Neste quadro aparecem cenários com imagens de coleções para simbolizar pesquisas já realizadas e, ao entrar na HUD do quadro (Figura 5), estão dispostos botões e imagens dos respectivos itens. Cada botão permite acessar um painel interno específico e, também, importar imagens criadas e desenhadas pelo usuário (o aluno).

Programação: Consiste em um série de sobreposições de HUD no canvas, onde o usuário (o aluno) entrará no painel principal e terá as opções citadas acima para seguir. Também encontrará botões para importar imagens e, para isso, cada título terá ao seu lado um botão de exclamação onde guiará o usuário (o aluno) de maneira que ele salve a imagem criada numa pasta no desktop e a nomeie conforme o pedido.

Arte: Para a arte, criou-se uma sala de reuniões, onde foi colocado o quadro de pesquisas, puffs e manequins.

Figura 4 - Sala de pesquisas para montagem de imagens no painel

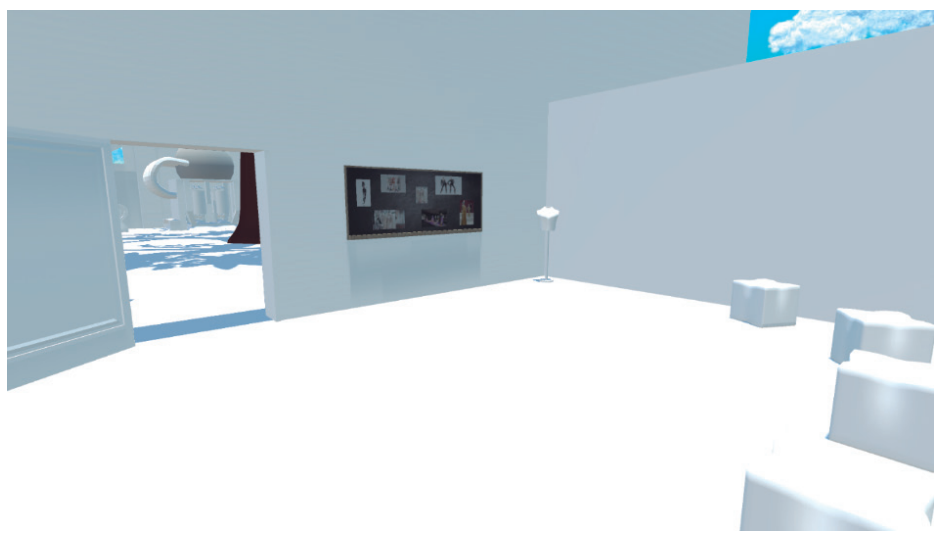


Figura 5 -HUD que aparecerá ao aluno quando interagir com o quadro na sala de reuniões.

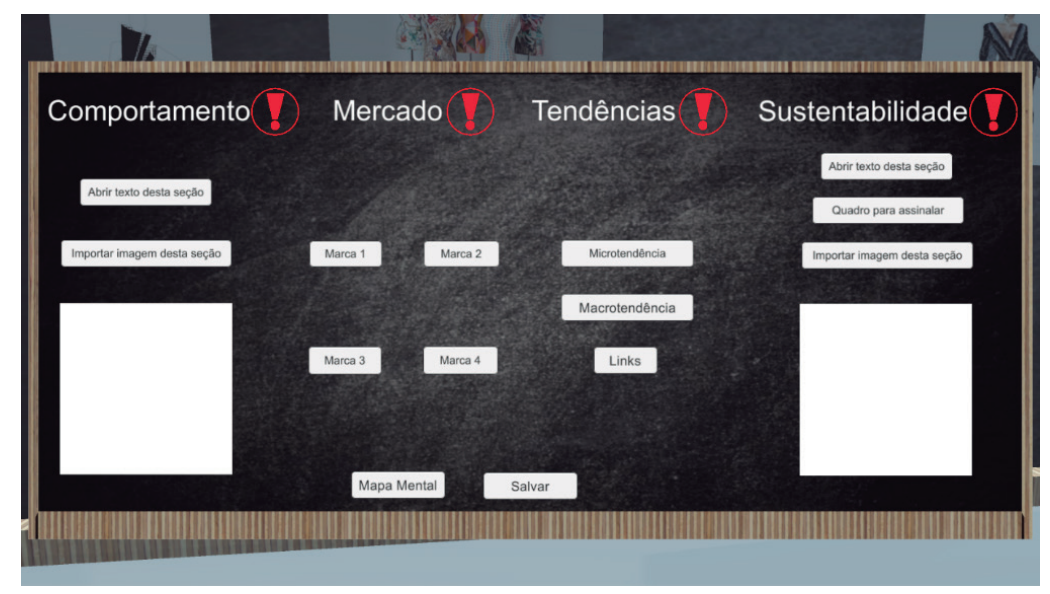

\section{Etapa 3 - Coleção de moda}

Game Design: Esta etapa se encontra a criação da coleção em si, aqui o usuário (o aluno) irá criar o conceito da coleção, lifestyle, referências, materiais e aviamentos, design de superfície, cores, mapa e release da coleção. O usuário (o aluno) combinará imagens com cores para fazer variações da mesma e poderá importar aviamentos para criação ou personalização das peças e, no final, terá sua coleção pronta com diferentes peças, cores e acessórios.

Programação: No mesmo estilo da etapa 2, esta funciona com sobreposições de HUD (Figura 6) e importações de imagens criadas pelo usuário.

Arte: Para esta etapa utilizou-se um painel de acesso no cenário, simbolizando um computador.

Figura 6 - HUD que aparecerá ao aluno quando interagir ao mini computador na sala de manequins.

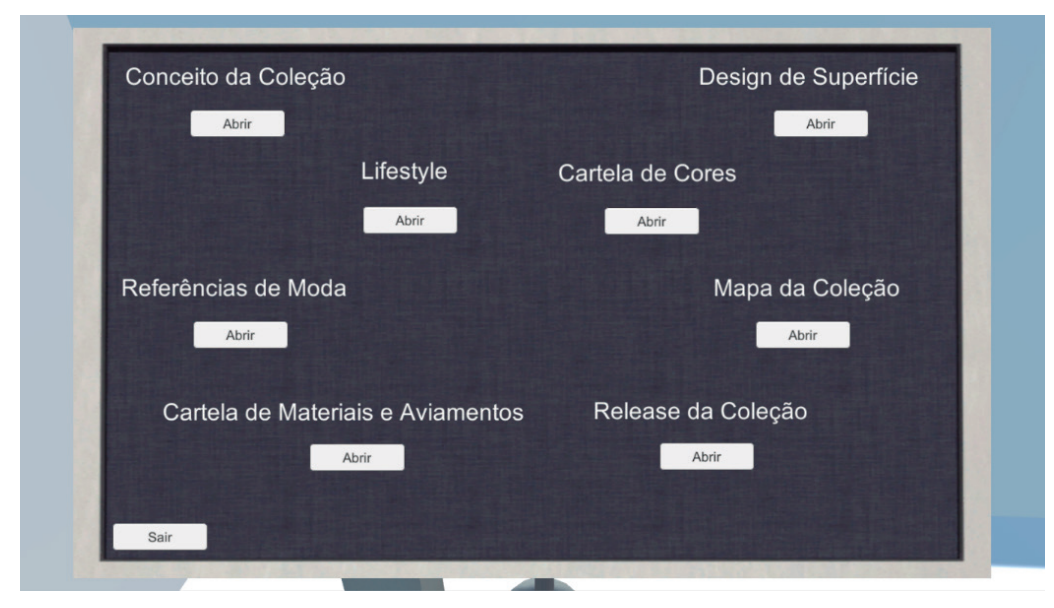

E, na finalização da atividade, será proporcionado um cenário de desfile da Coleção de Moda dos estudantes, quando todos disponibilizam a etapa final de todo o processo criativo desencadeado durante o percurso que a ferramenta digital de ensino proporcionou. Assim, além de divertir e dinamizar serve para contextualizar o conhecimento e tende a facilitar a formação de grupos em torno de um interesse comum. Poderá, ainda, criar uma atmosfera de cooperação 
positiva e motivadora, que favoreça descobertas coletivas e propicie uma relação dinâmica e interativa com o processo de aprendizagem.

Por fim, torna-se importante mencionar que, durante o processo de desenvolvimento d, ferramenta, ele pode sofreu diversas mudanças, pois, algumas vezes, percebeu-se que o jogo não funcionou da forma prevista somente após a sua estruturação. Isso ocorreu pelo fato de que alguns detalhes escapam da percepção do aluno desenvolvedor e dos professores orientadores, quando o jogo estava sendo criado. No entanto, cabe destacar que, a maior parte dos problemas no desenvolvimento dos jogos é detectada ainda na fase de testes realizados pela própria equipe.

\section{CONCLUSÕES}

A proposta deste projeto ancora-se, em primeiro lugar, no cenário de mudanças e a prática docente tem grande potencial para renovar a educação e sob este aspecto, acredita-se que a inserção das tecnologias no ensino torna mais fácil realizar atividades de pesquisa, de produção e de troca de conteúdo, ampliando as possibilidades já existentes.

O objetivo foi desenvolver uma ferramenta de ensino e aprendizagem para proporcionar a inovação no planejamento e desenvolvimento de Coleção de Moda e para isso foi necessário pesquisar as possibilidades de modelagem dos cenários, dos ambientes virtuais e dos objetos e, por fim, optou-se pelo software 3Ds Max".

Os principais atributos da ferramenta são a colaboração e a interação e contemplam todas as etapas para o planejamento, a criação e o desenvolvimento de uma coleção de produtos de Moda até o desfile de lançamento, de forma digital e interativa, envolvendo professores e alunos e caracterizando o ensino híbrido.

A ferramenta visa à autonomia, ao protagonismo do acadêmico, ou seja, ele é parte atuante na ferramenta e, portanto, está representado na primeira pessoa, quando a câmera simula o olhar do jogador. Dessa maneira, o estudante (Designer de Moda) pode visitar os ambientes, preencher e executar as tarefas como se estivesse no ambiente.

A ferramenta valoriza o pensamento e a inteligência visual por meio das representações dos painéis, como recursos imagéticos que estimulam a criatividade, e são úteis na síntese de referências que serão interpretadas em cores, texturas e formas na fase da criação.

\section{REFERÊNCIAS}

AVELAR, Suzana. Moda, Globalização e Novas Tecnologias. 2. ed. Rio de Janeiro: Editora Senac, 2009. 
BARCARO, Andrea. Os processos de uma empresa de moda. In: SORCINELLI, Paolo (org.).

Estudar a moda: corpos, vestuários, estratégias. São Paulo: Senac, 2008.

BOTELHO, Luiz. Jogos educacionais aplicados ao e-learning. Disponível em: https://bit.ly/35dKtWk. Acesso em: 14 jul. 2020.

CASTELLS, Manuel. A sociedade em rede. v.1. São Paulo: Paz e Terra, 1999.

CHANDLER, Heather Maxwell. Manual de produção de jogos digitais. Porto Alegre: Bookman, 2012.

CURVEllo, J. J. A. O ensino de teorias da Comunicação Organizacional em cursos de Comunicação no Brasil. Revista Internacional de Relaciones Públicas, n. 15, v. VIII, 2018. p. 63-84.

GROSSI, Márcia Gorett Ribeiro; MURTA, Flávio Cançado; SILVA, Mislene Dalida. A Aplicabilidade das Ferramentas Digitais da Web 2.0 no Processo de Ensino e Aprendizagem. Revista Contexto \& Educação. Ano 33. Nr. 104.Jan./Abr. 2018. P. 33-59.

GUERRERO, José Antonio. Novas Tecnologias Aplicadas à Moda: Design, Produção, Marketing e Comunicação. Ceará: Editora Senac, 2015.

HUNDERTWASSER, F. Mouldiness: manifesto against rationalism in architecture. 1964. Disponível em: https://bit.ly/3pfkJR4. Acesso em: 17 fev. 2020.

JONES, Sue Jenkyn. Fashion design: manual do estilista. 2. ed. São Paulo: Cosac Naify, 2005.

MACHADO, Liliane dos Santos et al.. Serious Games Baseados em Realidade Virtual para Educação Médica. Revista Brasileira de Educação Médica. 2010. p. 254-262.

MONTEMEZZO, Maria C. F. S. Diretrizes metodológicas para o projeto de produtos de moda no âmbito acadêmico. Dissertação (Mestrado em Desenho Industrial) - Faculdade de Arquitetura, Artes e Comunicação, Universidade Estadual Paulista, Bauru, 2003.

MORAES, Dijon de. Metaprojeto: o design do design. São Paulo: Blucher, 2010.

OLIVEIRA, Grazyella. Moda e Hipermídia: Entretece de Linguagens Rítmicas. São Paulo: Editora Santarém, 2014. 
RENFREW, Elinor; RENFREW, Colin. Desenvolvendo uma coleção. Porto Alegre: Bookman, 2010.

SANCHES, Maria Celeste de F. Moda e Projeto: Estratégias metodológicas em Design. 1. ed. São Paulo: Estação das Letras, 2017.

SILVA, João Carlos da; AGUIAR, Fábio Calciolari. 3ds Max 9: prático e ilustrado. São Paulo: Érica, 2010.

SILVEIRA, Sidnei Renato; BARONE, Dante Augusto Couto. Jogos Educativos computadorizados utilizando a abordagem de algoritmos genéticos. UFRGS. Instituto de Informática. Curso de Pós-Graduação em Ciências da Computação. 1998.

SORGER, Richard; UDALE, Jenny. Fundamentos de design de moda. Porto Alegre: Bookman Companhia, 2009.

TREPTOW, Doris. Inventando moda: planejamento de coleção. Brusque: Doris Treptow, 2013.

VILA, Magda; SANTANDER, Marli. Jogos cooperativos no processo de aprendizagem acelerada. Rio de Janeiro: Qualitymark, 2013. 